\title{
Capsule Commentary on Pham-Kanter et al., Public Awareness of and Contact with Physicians Who Receive Industry Payments: A National Survey
}

\author{
Susannah L. Rose, PHD \\ Cleveland Clinic, Department of Bioethics, Office of Patient Experience, Case Western Reserve University, Cleveland, OH, USA.
}

J Gen Intern Med 32(7):797

DOI: $10.1007 / \mathrm{s} 11606-017-4045-7$

() Society of General Internal Medicine 2017

$\mathrm{M}$ ore than 600,000 physicians in the United States have financial relationships with for-profit industry. ${ }^{1}$ Significant efforts have been made by medical centers, physicians, state and federal governments, and industry toward making these conflicts of interest (COI) more transparent. But have these efforts been successful in improving patients' awareness of such COI among their physicians? Do people even know that this information exists? The study conducted by Pham-Kanter et al. sought to find the answer to these questions. ${ }^{2}$ The authors assessed the knowledge among the general U.S. population regarding their physicians' relationships with industry. The study found that patients commonly received care from physicians who had industry relationships; in fact, $65 \%$ saw physicians who had received industry payments within the previous 12 months. However, despite this high percentage, very few patients were aware that the information was publically available, or that their own physicians had such relationships. Not unexpectedly, patients with a higher level of education, those with significant diseases, and those who lived in states with public disclosure laws were more likely to be aware of their physicians' COI.

Importantly, the study employed an innovative methodology, using a nationally representative sample from a household survey panel. Previously published studies have most commonly used samples derived from one institution or at a more local level, or have focused on narrow diagnostic groups. The method used by Pham-Kanter and colleagues will allow us to compare future findings against these results, enabling policymakers and researchers to better determine whether improved transparency efforts are working.

This study is significant in that we now know that patients have very little awareness of $\mathrm{COI}$ among their physicians, and that more needs to be done to improve patients' knowledge and understanding. In particular, given that some patients were more knowledgeable than others, the study shows that certain categories of patients may need additional education or other intervention to facilitate their access to this important information. Future studies should focus on how to improve patients' knowledge and access to information, and these efforts can be initiated by the federal government, as the authors recommend, or by physicians and medical centers themselves.

Corresponding Author: Susannah L. Rose, PHD; Cleveland Clinic, Department of Bioethics, Office of Patient Experience, Case Western Reserve University, Cleveland, OH, USA (e-mail: Roses2@ccf.org).

\section{Compliance with Ethical Standards:}

Conflict of Interest: The author declares that she does not have a conflict of interest.

\section{REFERENCES}

1. Agrawal S, Brown D. The Physician Payments Sunshine Act-two years of the open payments program. N Engl J Med. 2016;374(10):906-9.

2. Pham-Kanter G, Mello MM, Lehmann LS, Campbell EG, Carpenter D. Public awareness of and contact with physicians who receive industry payments: a national survey. J Gen Intern Med. 2017. doi:10.1007/ s11606-017-4012-3. 